Notas y Comentarios

\title{
Criminalización, separación familiar y reemigración a Estados Unidos de varones mexicanos deportados
}

\section{Criminalization, family separation and re-migration to the United States of deported Mexican men}

Eduardo Torre Cantalapiedra*

Luis Enrique Calva Sánchez**

\section{Resumen}

Mediante el uso de datos de la Encuesta sobre Migración en la Frontera Norte de México, analizamos cómo varían las intenciones de regresar a Estados Unidos de los varones deportados por las autoridades migratorias de aquel país en función de cómo son afectados por el sistema de deportación -que criminaliza a los migrantes en situación irregular y su reingreso al territorio estadounidense-y según los integrantes de sus familias que se quedaron en aquel pais tras la deportación. Adicionalmente, examinamos las cifras de deportaciones, prohibiciones de reingreso, separaciones familiares e intenciones de reingreso.

Palabras clave: migración internacional; política migratoria; patrones migratorios; separación familiar; deportación; criminalización; reingreso en Estados Unidos.

* El Colegio de la Frontera Norte, sede Tijuana / Cátedras Conacyt. Dirección: Carretera escénica Tijuana - Ensenada, Km 18.5, San Antonio del Mar, 22560, Tijuana, Baja California, México. Correo: etorre@colef.mx ORCID: https://orcid. org/0000-0002-4074-3752

** El Colegio de la Frontera Norte, sede Monterrey. Dirección: Técnicos 277, Tecnológico, 64700, Monterrey, N.L., México. Correo: lecalva@colef.mx ORCID: https://orcid.org/0000-0002-7037-5874 


\begin{abstract}
By using data from the Survey on Migration in the Northern Border of Mexico, we analyze how the intentions to return to the United States of the men deported by the immigration authorities of that country vary, according to how they are affected by the deportation system, that criminalizes the undocumented migrants and their re-entry into the US territory and according to the members of their families who remain in that country after deportation. Additionally, we examine the figures of deportations, family separations, prohibitions of re-entry and intentions of re-entry.

Keywords: international migration; immigration policy; migratory patterns; familiar separation; deportation; criminalization; re-entry in the United States.
\end{abstract}

\title{
Introducción
}

A mediados de 2018, distintos medios de comunicación de Estados Unidos, de México y del resto del mundo dieron una gran cobertura a la política de separación de familias que la administración de Donald Trump aplicó con los migrantes en situación irregular recién llegados a dicho país. Tal forma de proceder fue criticada por amplios sectores de la sociedad estadounidense y de otros países, por lo que finalmente fue revocada por el presidente Trump (Shear, Goodnough y Haberman, 2018). Sin embargo, este acontecimiento sólo es una de las varias formas en que la política migratoria de Estados Unidos produce la separación familiar, pues también provoca la deportación de migrantes que ya residen en ese país, quienes son expulsados como si se tratase de auténticos criminales. Estas deportaciones se han traducido en que, año con año, miles de personas queden separadas, temporal o permanentemente, de sus cónyuges, hijas/os y otros familiares.

Para entender en un sentido más completo las vicisitudes que enfrentan los migrantes tras la deportación, debemos remontarnos a los años noventa, cuando comenzaron a delinearse las dos metas más relevantes de la política de control de la inmigración indocumentada de Estados Unidos: 1) disuadir y detener los cruces de indocumenta- 
dos, y 2) reducir el número de indocumentados ya establecidos en su territorio. Para alcanzarlas, los sucesivos gobiernos estadounidenses han seguido dos grandes ejes en sus políticas: $i$ ) el reforzamiento del control fronterizo -incluida la militarización de su frontera- (Cornelius, 2007), y ii) el incremento de las remociones o deportaciones formales (Hagan, Rodríguez y Castro, 2011; Rosenblum et al., 2014), articuladas a través de una estrategia de criminalización de la inmigración. ${ }^{1}$

La ley de inmigración estadounidense ha pasado de ser mayormente un proceso administrativo civil, a constituirse en un sistema que se entrelaza con la ley criminal, puesto que, entre otros cambios, las violaciones a la ley de migración son ahora criminales cuando antes eran civiles, o bien, tienen consecuencias criminales mayores cuando ya antes eran tratadas de esa manera (Stumpf, 2006). Así, el modus operandi del sistema de deportación estadounidense actual es hacer que el cruce y la residencia indocumentada en aquel país tengan consecuencias administrativas y penales que pueden llegar a ser muy graves (Hagan, Rodríguez y Castro, 2011; Márquez Covarrubias, 2013; Slack et al., 2015; Argueta, 2016; Abrego et al., 2017).

En 1996, la Illegal Immigration Reform and Immigrant Responsibility Act (IIRIRA) expandió las categorías de extranjeros susceptibles de deportación, incrementando las ofensas por las que los inmigrantes podrían ser deportados y restringiendo la posibilidad de evitar este proceso (Hagan, Eschbach y Rodriguez, 2008; Meissner et al., 2013). Además, en función de la razón de la deportación, les

${ }^{1}$ La criminalización no sólo se reduce a los textos legales y a su aplicación práctica, sino que se produce y reproduce en los planos discursivo y simbólico. Las acciones de encarcelamiento y expulsión de una población que lleva décadas viviendo en territorio estadounidense se hacen "necesarias" si se considera a sus integrantes como criminales peligrosos. En este sentido, no es de extrañar que frecuentemente términos referidos a las personas con estatus migratorio irregular y a los criminales, sean empleados como sinónimos (Ewing, Martínez y Rumbaut, 2015). Así, la construcción social del migrante como criminal tiene su máxima expresión en los migrantes deportados, a quienes los discursos de las autoridades y de los medios periodísticos estigmatizan no sólo en Estados Unidos, sino también en México (como se puede observar en diversos trabajos, como los de Ewing, Martínez y Rumbaut, 2015; Abrego et al., 2017; Albicker y Velasco, 2016). 
prohíbe el reingreso a Estados Unidos por un periodo de cinco años o más (Hagan, Eschbach y Rodriguez, 2008; Hagan, Rodriguez y Castro, 2011). Argueta (2016) señala que, a partir de 2005, el U.S. Customs and Border Protection puso en funcionamiento la estrategia de Consequence Delivery System que, frente a los retornos voluntarios sin castigo, ${ }^{2}$ implicó: 1) más remociones (removal) o deportaciones formales que generalmente impiden solicitar una visa y hacen que la reentrada no autorizada a Estados Unidos pueda implicar cargos criminales; y además, se amplía el uso de las remociones expeditas recogidas en IIRIRA (1996); 2) se incrementa la proporción de personas a las que se les imponen cargos criminales; 3) se llevan a cabo programas de expedición remota, como Alien Transfer and Exit Program, así como Mexican Interior Repatriation Program. ${ }^{3}$

La Operación Streamline (2005) tiene como objetivo explícito criminalizar todo cruce fronterizo no autorizado, y es una iniciativa conjunta del Departamento de Seguridad Nacional y del Departamento de Justicia (DHS y DOJ, respectivamente, por sus siglas en inglés).

El punto clave de todo este sistema punitivo es desincentivar la reincidencia en el cruce indocumentado (Slack et al., 2015; Argueta, 2016), puesto que, si los migrantes previamente deportados que regresan de manera no autorizada a Estados Unidos -incluidos los que buscan reunirse con sus familiares en ese país- son detenidos por las autoridades estadounidenses, podrían enfrentar multas y penas de prisión (Argueta, 2016). Por lo tanto, es relevante el estudio de cómo las políticas antiinmigrantes y que criminalizan a los migrantes afectan los planes de movilidad y las movilidades de los deportados (véase, por ejemplo, Amuedo Dorantes y Pozo, 2014; Martínez, Slack y Martínez-Schuldt, 2018).

Otra de las tendencias recientes más importantes en la política migratoria estadounidense es el incremento de las deportaciones en el interior del territorio estadounidense; también resalta que cada vez es menor la proporción de mexicanos deportados y entrevistados

${ }^{2}$ Más allá del castigo que supone la expulsión en sí misma.

${ }^{3}$ Esta manera de proceder fue adoptada oficialmente en el año 2011 (Martínez, Slack y Martínez-Schuldt, 2018). 
por la Emif Norte que intentarían regresar a Estados Unidos (Calva Sánchez y Alarcón Acosta, 2018). Ya sea de modo intencionado o no, este tipo de deportaciones trae consigo la separación familiar, fenómeno que frecuentemente conduce a nuevas movilidades. Dado que la experiencia de la separación familiar genera múltiples consecuencias negativas para los miembros de las familias (Wessler, 2011; American Immigration Council, 2012; Dreby, 2012; Capps et al., 2015; Torre Cantalapiedra y Rodríguez Gutiérrez, 2019) y debido a que éstas prefieren permanecer juntas, dejar familiares atrás podría constituir un gran aliciente para considerar reemigrar a Estados Unidos, como lo muestran algunos trabajos para los casos de los migrantes centroamericanos y mexicanos que quedaron separados de sus familiares tras un proceso de deportación (Hagan, Eschbach y Rodriguez, 2008; Amuedo-Dorantes, Pozo y Puttitanun, 2015; Cardoso et al., 2016).

A pesar de que el mayor porcentaje de deportados se ha producido entre los migrantes originarios de México (Martínez, Slack y Martínez-Schuldt, 2018), que en su gran mayoría son varones (Golash-Boza y Hondagneu-Sotelo, 2013; Calva Sánchez y Alarcón Acosta, 2018), ${ }^{4}$ y que entre éstos ha disminuido drásticamente la intención de reingresar a Estados Unidos, sólo un reducido número de trabajos examinan las decisiones de reemigrar de esta población (Martínez, Slack y Martínez-Schuldt, 2018).

El objetivo de este trabajo es analizar cómo el sistema de deportación -que criminaliza a los migrantes indocumentados y su reingreso al territorio estadounidense- y el que las familias queden separadas, está asociado con la intención de reemigrar entre los varones mexicanos que tienen su residencia en aquel país y que fueron deportados por las autoridades estadounidenses. Para su logro, este trabajo está dividido en cuatro secciones. En la primera, a modo de contextualización, se analizan las cifras de deportaciones de varones, las que conllevan la prohibición de retornar y las que suponen las separaciones de sus hijas/os menores de 18 años y de sus parejas. En la segunda, se examina la literatura sobre reemigración de migrantes

${ }^{4}$ Calva Sánchez y Alarcón Acosta (2018) estiman, con datos de la Emif Norte, que en 2016 el 88.8\% de los deportados mexicanos eran varones. 
deportados, prestando especial atención a los hallazgos respecto a la puesta en funcionamiento de un sistema de deportación que criminaliza a los inmigrantes indocumentados, y a los lazos familiares que tienen estas personas en Estados Unidos. En la tercera sección se presenta la fuente de datos empleada, que es la Encuesta sobre Migración en la Frontera Norte (Emif Norte), así como la metodología seguida. En la cuarta, se analiza, mediante estadística descriptiva y modelos estadísticos multivariados, cómo el sistema de deportación que criminaliza a los migrantes indocumentados y el dejar atrás a miembros de su familia se asocia con la intención de reingresar a Estados Unidos entre los varones deportados.

\section{Deportaciones, prohibiciones y separaciones: algunas cifras}

Existen dos fuentes fundamentales para el análisis de las deportaciones de mexicanos por parte de las autoridades estadounidenses: los registros administrativos del DHS y los datos de la Emif Norte. En este apartado aprovechamos las ventajas que ofrece cada una de ellas para aproximarnos cuantitativamente al fenómeno de las deportaciones entre los años 2000 y 2018, periodo en el que hubo cambios considerables en el monto anual de eventos, en las características de los migrantes y, sobre todo, en las consecuencias de las deportaciones, tales como las separaciones familiares y las prohibiciones de reingresar.

En la Gráfica 1 se presenta el monto de expulsiones que reporta el DHS (por remoción o retorno) y el número de capturas de migrantes en la frontera suroeste que reporta el U.S. Customs and Border Protection (CBP). El análisis de estos datos evidencia varios resultados relevantes. Primero, el descenso en el monto de eventos de personas mexicanas expulsadas por autoridades estadounidenses: la cifra más reciente que reporta el DHS es 232 mil eventos para el año fiscal 2017, cifra muy inferior a la observada en 2000, cuando ascendió a más de 1.5 millones. Destaca además la correlación positiva entre el monto de expulsiones y de aprehensiones que realiza la patrulla fronteriza en la frontera suroeste de Estados Unidos (véase la línea negra en la Gráfica 1), por lo que no es muy aventurado sugerir que el 
descenso observado en las expulsiones no se debe a que el gobierno estadounidense haya desistido en sus esfuerzos por capturar y expulsar migrantes; lo que ha sucedido -al menos para los mexicanos-es que ha disminuido drásticamente la cantidad de personas que buscan ingresar sin documentos.

\section{Gráfica 1}

Volumen de mexicanos expulsados por autoridades estadounidenses, según el proceso de deportación, 2000-2018

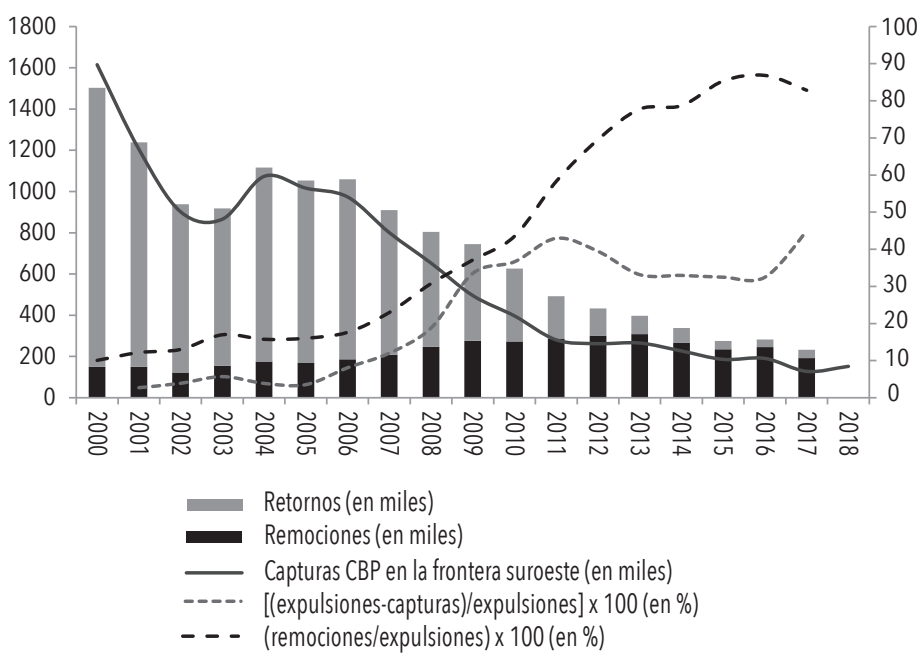

Fuentes: Elaboración propia con base en los datos de United States, Department of Homeland Security, Office of Immigration Statistics, 2018.

Otro aspecto que cabe destacar en la Gráfica 1 es el crecimiento de las remociones (removals) o deportaciones formales - expulsión de extranjeros con base en una orden de deportación formal-, tanto en magnitud absoluta como en su importancia relativa respecto al monto total de expulsiones. Se estima que en el año 2000 sólo $10 \%$ de las expulsiones de nacidos en México se realizó mediante un proceso de remoción; sin embargo, dicho porcentaje aumentó constantemente hasta alcanzar un punto máximo en 2016 , cuando fueron $87 \%$ de los eventos. Por lo tanto, se puede afirmar que un porcentaje mayor 
de migrantes sufren las consecuencias de ser expulsados de Estados Unidos, incluyendo la prohibición de reingresar a aquel país por periodos de tiempo que van desde los cinco años hasta de por vida (como se constata posteriormente en la Gráfica 3).

Finalmente, respecto a la Gráfica 1, se debe destacar la relación entre el monto de expulsiones y el número de capturas en la frontera suroeste. Entre los años 2000 y 2005 la diferencia entre ambos era relativamente pequeña: menor a $6 \%$ respecto al total de expulsiones; sin embargo, a partir del último año la diferencia aumentó hasta alcanzar un máximo en 2011, cuando representó el $43 \%$ respecto al total de expulsiones; posteriormente descendió a 32\% en 2016, pero en 2017 nuevamente aumentó hasta 44.9\%. Por lo anterior, se puede afirmar que las capturas en el interior de Estados Unidos explican cada vez más el monto de expulsiones de mexicanos desde ese país, lo que muestra parte de los efectos de la política migratoria dentro de Estados Unidos respecto a incrementar y reforzar las medidas para identificar y expulsar a las personas indocumentadas que ya residen en ese país.

Las expulsiones de migrantes desde el interior de Estados Unidos afectan tanto a hombres como a mujeres mexicanas que residen en ese país, aunque el monto de los varones suele ser considerablemente mayor. Lo anterior se puede demostrar con datos de la Emif Norte, pues entre sus poblaciones de estudio está la expulsada por las autoridades estadounidenses. La encuesta recopila datos de parte de la trayectoria migratoria de las y los mexicanos, por lo que se puede identificar si su país de residencia es México o Estados Unidos (véase la Gráfica 2). ${ }^{5}$ Las cifras anuales para el periodo 2000-2018 muestran que en 2011 se produjo un máximo en el monto y porcentaje de los eventos asociados a expulsiones de personas que ya residían en Estados Unidos (49\%); si el porcentaje se calcula por separado para

${ }^{5}$ La Emif Norte permite distinguir a los migrantes que residen en México y a los que residen en Estados Unidos utilizando dos criterios: la propia declaración del migrante, o el tiempo de última estancia en dicho país. En este caso, siguiendo la lógica establecida en trabajos previos (Calva Sánchez y Coubès, 2017), se determina que el migrante es residente en Estados Unidos si su última estancia -esto es, la previa a la deportación- en aquel país fue al menos de un año y/o si se declara como residente de ese país; de lo contrario, se le considera residente en México. 
hombres y mujeres, se identifica que entre los primeros aumenta a $52 \%$, mientras que para ellas desciende a $30 \%$. En casi todo el periodo analizado, el porcentaje de residentes en Estados Unidos respecto al total de expulsiones es más alto para la población masculina (véase la línea negra en la Gráfica 2).

\section{Gráfica 2}

Eventos de migrantes varones mexicanos expulsados por autoridades estadounidenses a México, según país de residencia; 2000-2018

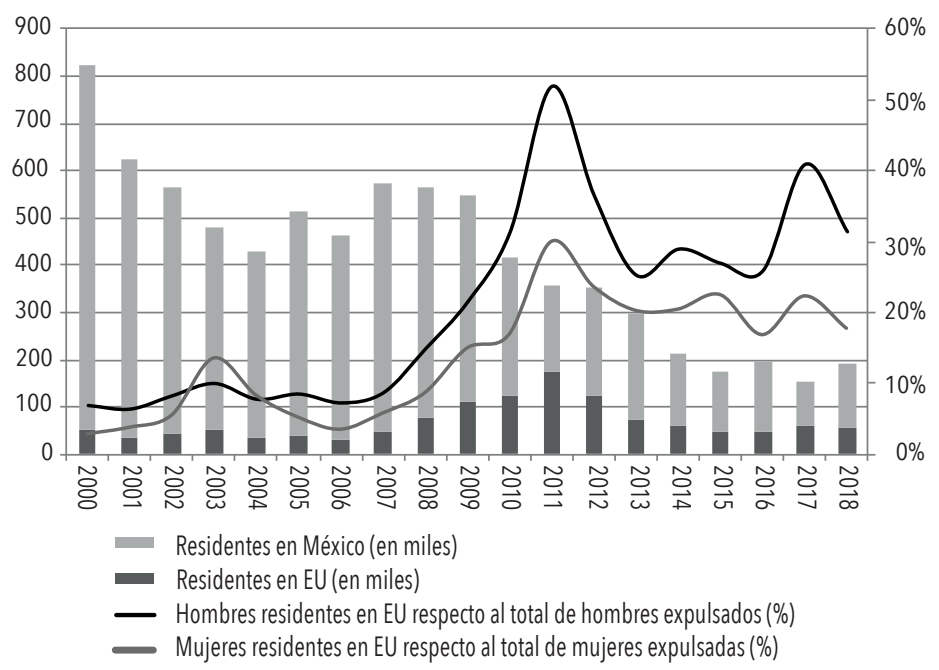

Fuente: Elaboración propia con base en datos en la EMIF Norte, 2000-2018.

Con base en las gráficas anteriores, se puede afirmar que ha habido un incremento en las remociones en el caso de los mexicanos expulsados desde Estados Unidos, y con esto ha aumentado el porcentaje anual de migrantes que reciben un castigo que limita su posibilidad de obtener algún visado para reingresar a ese país. En la Emif Norte se pregunta a los encuestados si debido a su deportación recibieron algún castigo, pero sólo se tienen datos para 2017 y 2018. En la Gráfica 3 se presentan los datos según el país de residencia del migrante. En ambos años se identifica que, entre los residentes en Es- 
tados Unidos, la gran mayoría (78\% en 2018) recibió un castigo. En el caso de los residentes en México - probablemente la mayoría expulsados por intentar ingresar sin documentos--, destaca que también hay un porcentaje considerablemente alto de quienes recibieron algún castigo (54\% en 2018). Estos datos permiten concluir que, efectivamente, la mayoría de la población de varones expulsados desde Estados Unidos reciben algún tipo de castigo que les prohíbe la entrada a ese país por cierto tiempo.

\section{Gráfica 3}

Porcentaje de eventos de hombres mexicanos expulsados por autoridades estadounidenses, que declaran haber recibido un castigo que limita su entrada a Estados Unidos, según país de residencia del migrante; 2017 y 2018

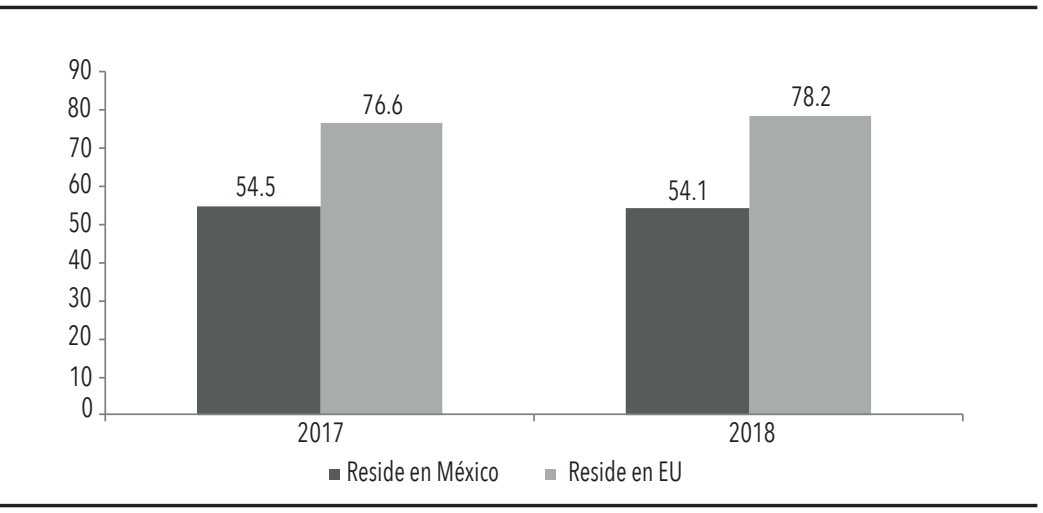

Fuente: Elaboración propia con base en datos en la EMIF Norte, 2017-2018.

Como ya fue mencionado, una parte de las expulsiones desde el interior de Estados Unidos involucra separaciones familiares. Los datos de la Emif Norte permiten dimensionar esta situación. En la Gráfica 4 se presentan indicadores sobre separación familiar de la población de hombres expulsados desde Estados Unidos según su país de residencia. Los tres indicadores son: porcentaje de quienes tienen hijos menores de 18 años de edad y que residen en Estados Unidos; porcentaje de quienes tienen hijos en ese país sin importar la edad; y porcentaje de quienes indican tener a su cónyuge en ese país. 


\section{Gráfica 4}

Porcentaje de eventos de hombres mexicanos expulsados por autoridades estadounidenses que tienen hijos/as o cónyuge en ese país, según país de residencia, 2010-2018

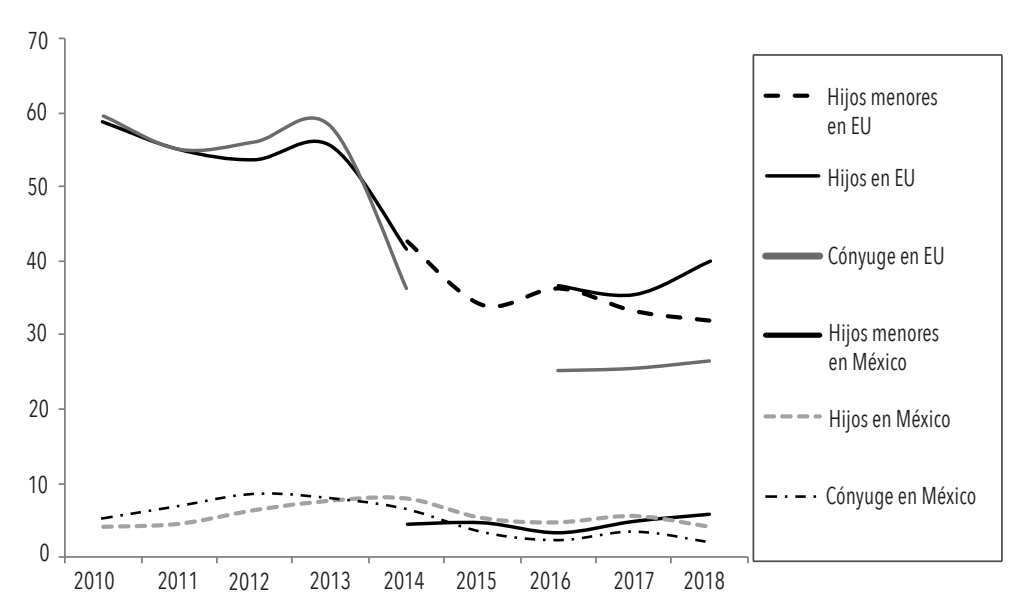

Nota: Al encuestado se les pregunta si tiene cónyuge viviendo en Estados Unidos, si tiene hijos y, a partir de 2014, se pregunta si tiene hijos menores de edad en ese país. En 2015 no se preguntó a los residentes en Estados Unidos si tenían familiares en ese país. Se define como residente en Estados Unidos a los expulsados que indican residir en ese país o a los que indican residir en México, pero su última estancia es de un año o más tiempo.

Fuente: Elaboración propia con base en datos en la EMIF Norte, 2010-2018.

Lo primero que resalta es la gran diferencia en los indicadores según el país de residencia del migrante. Como era de esperar, los porcentajes más altos se identifican entre los residentes en Estados Unidos: en 2010, cerca del 60\% de los hombres tenían cónyuge en ese país, mientras que entre los residentes en México el porcentaje es de apenas 5\%; el porcentaje de quienes tienen hijos es muy similar. El segundo aspecto que destaca es el descenso en la frecuencia con que se observan estas situaciones, ya que en 2018 los porcentajes disminuyeron, sobre todo para los residentes en Estados Unidos: sólo 40\% indicó tener hijos en ese país y únicamente 26.6 cónyuge. A partir de 2014 se pregunta en la encuesta sobre la presencia de hi- 
jos menores de edad; en ese año $42 \%$ respondió afirmativamente, y para 2018 disminuyó a 31\%.

Las cifras presentadas en este apartado permiten ofrecer un escenario de los efectos asociados a los cambios en las políticas migratorias de Estados Unidos por más de dos décadas, lo que posibilita argumentar que su política antiinmigrante es un proceso continuo que inició en administraciones pasadas, y muestra que, aunque parezca sorprendente, en la primera mitad de la administración de Trump no se superaron las cifras de expulsión de la administración anterior, al menos en el caso de los mexicanos. El efecto de las políticas de expulsión desde el interior fue mayor en 2011, y aunque el porcentaje descendió en 2018, el monto aún es superior a los observados a inicios de siglo. Estas expulsiones han supuesto que una gran parte de los varones mexicanos, especialmente los que residen dentro del territorio estadounidense, estén supeditados a un sistema de deportación que, entre otros aspectos, implica prohibiciones de reingresar a dicho país y/o que queden separados de alguno/os de sus familiares, por lo que es relevante identificar y analizar las implicaciones de ambas realidades sobre las decisiones de reemigrar a Estados Unidos o de buscar que los familiares regresen o migren a México.

\section{De la expulsión a la reemigración: el sistema de deportación y los vínculos familiares}

La reemigración de los mexicanos hacia Estados Unidos ha sido objeto de diversas investigaciones a lo largo del tiempo, aunque sin distinción del motivo del retorno (véase Massey y Espinosa, 1997; Massey y Riosmena, 2010). Sin embargo, se ha señalado que la deportación, como fenómeno de retorno forzoso, requiere de análisis específicos. ${ }^{6}$ En el caso que nos ocupa, hay evidencia sobre cómo

${ }^{6}$ La deportación es una categoría de análisis clave para entender la multitud de procesos migratorios que atañen a los migrantes que retornan a México, como la reinserción laboral (Mariscal Nava y Torre Cantalapiedra, 2018), el reingreso a Estados Unidos (Martínez, Slack y Martínez-Schuldt, 2018), las paternidades / maternidades a distancia, la separación familiar y la configuración de familias transnacionales (Dreby, 2012; Peláez Rodríguez y París Pombo, 2016), entre otros. 
el fenómeno de la reemigración difiere según la razón del regreso al lugar de origen (Calva y Coubès, 2017). Por lo tanto, no es de extrañar que, en los últimos años, conforme las políticas migratorias estadounidenses se han vuelto más restrictivas y persecutorias, se han desarrollado varios trabajos centrados de manera específica en la reemigración de los deportados, tanto para el caso de mexicanos como de centroamericanos.

En esta literatura se han destacado principalmente dos aspectos: el funcionamiento de las políticas migratorias estadounidenses, principalmente en cuanto a su dinámica de deportar y criminalizar a los migrantes, y los lazos familiares de los deportados, en especial de quienes dejen atrás miembros con los que han establecido vínculos afectivos (véase, por ejemplo, Amuedo-Dorantes, Pozo y Puttitanun, 2015; Peláez Rodríguez y París Pombo, 2016; Cardoso et al., 2016, Martínez, Slack y Martínez-Schuldt, 2018).

Las políticas migratorias estadounidenses que sostienen al sistema de deportación que criminaliza al migrante han sido extensamente examinadas en los trabajos sobre reemigración. Amuedo-Dorantes y Pozo (2014) analizan la influencia de ciertas políticas migratorias sobre las intenciones de reemigrar de los mexicanos (a nivel federal examinan la Operación Streamline; y en el ámbito estatal, las legislaciones que incorporan diversas disposiciones al respecto en un solo texto legal). Encuentran que las detenciones de la Patrulla Fronteriza que mantiene vigente la Operación Streamline, no tienen un impacto estadísticamente significativo sobre los intentos de retornar a Estados Unidos. En contraste, el hecho de que la detención del migrante haya sido en un estado con una legislación que incorpora diversas disposiciones en un sólo texto legal en contra de los migrantes, tiene efectos en la disminución de las intenciones de retorno en el muy corto plazo, pero adquiere el efecto contrario en el largo plazo.

En contraste con lo anterior, Dorantes, Pozo y Puttitanun (2015) prueban el efecto que la aplicación de la ley de migración promovida por estados y localidades tiene sobre la intención de reemigrar de la población centroamericana deportada por Estados Unidos, y encuentran que, lejos de tener un efecto negativo, tales políticas dentro del territorio suponen un incremento en la propensión a mostrar la intención de retornar. 
Por su parte, Martínez, Slack y Martínez-Schuldt (2018) ponen a prueba al mismo tiempo varias de las políticas federales que siguen la lógica del Consequence Delivery System (Alien Transfer and Exit Program, Operación Streamline, Mexican Interior Repatriation Program, y Comunidades Seguras), así como el hecho de que los migrantes pasen más de una semana detenidos. Concluyen que, si bien algunas de ellas pueden tener algún efecto en la disuasión de los planes de retorno, no tienen mayor repercusión en la disuasión en el largo plazo.

A diferencia de estas investigaciones, más interesadas en si las políticas migratorias de Estados Unidos son eficaces y si cumplen con sus objetivos, en la presente queremos observar cómo las sanciones negativas que llevan aparejadas estas medidas afectan a los planes de los migrantes respecto a regresar al territorio estadounidense. Asimismo, consideramos que la denominación Consequence Delivery System es eufemística, puesto que en realidad las llamadas "consecuencias" no son sino el tratamiento de los migrantes como si fueran verdaderos delincuentes a los que habría que corregir mediante los correspondientes castigos. ${ }^{7}$ Por lo anterior, resulta preferible hablar de un sistema de deportación que criminaliza a los inmigrantes en situación irregular, que afecta tanto a aquellos que tratan de cruzar a Estados Unidos por primera vez como a los que llevan años, o incluso décadas, residiendo en el territorio estadounidense.

El sistema de deportación mencionado tiene dos elementos que consideramos pueden resultar fundamentales para la labor de disuasión de nuevos cruces: por un lado, conlleva tiempos de privación de la libertad que pueden prolongarse por semanas, en los cuales los migrantes reciben un tratamiento similar al de los criminales, aunque se trate del procesamiento por "delitos" de tipo migratorio; en otras palabras, quienes tienen experiencias de privación de la libertad y de todo lo que ello acarrea, pueden querer evitar encontrarse nuevamente en tal situación. Por otro lado, el castigo que pretende limitar las nuevas entradas a los migrantes deportados mediante la prohibición

${ }^{7}$ Los diferentes castigos (sanciones negativas) -entre ellos el encarcelamiento- tratan de promover la conformidad con las normas y disuadir de aquellos comportamientos contrarios a las mismas (Giddens, 2000). 
de reingresar a Estados Unidos bajo la amenaza de enfrentar cargos criminales y posible encarcelamiento, resulta clave para el entendimiento de las decisiones de reingreso de los migrantes -sobre todo para quienes, siendo conscientes de las posibles consecuencias de las mismas, lo reportan en las encuestas-; sin embargo, esto no ha sido nunca puesto a prueba en los estudios, salvo de un modo indirecto a través de ciertos programas (por ejemplo, la Operación Streamline), por lo que su análisis constituye una de las grandes aportaciones de este trabajo.

Diversas investigaciones cualitativas han puesto de manifiesto que familias mexicanas en Estados Unidos, tras sufrir la deportación de uno de sus miembros, buscan la manera de estar nuevamente juntos en aquel país y encuentran dificultoso o indeseable reintegrar a la familia en México (Morales Guzmán, 2010; Ruiz Marrujo, 2014; Peláez Rodríguez y París Pombo, 2016). Asimismo, hay indicios de que, conforme pasan los años, los deportados enfrentan mayores dificultades para reingresar a Estados Unidos debido tanto al endurecimiento de las políticas de control fronterizo y del sistema de deportación que criminaliza a los migrantes, como a la acumulación de un historial de deportaciones y castigos.

Los trabajos de este tipo incluyen un número muy reducido de casos analizados a profundidad, por lo que no permiten realizar generalizaciones respecto de la reemigración tras la deportación; pero ello sí es posible en los trabajos cuantitativos que han analizado este fenómeno migratorio - bajo diferentes denominaciones, como "reemigración", "reingreso" o "migración repetida"- tanto para la población mexicana como para la centroamericana (Amuedo-Dorantes y Pozo, 2014; Bojórquez Chapela, González Fagoaga y Guillén López, 2014; Cardoso et al., 2016; Martínez, Slack y Martínez-Schuldt, 2018).

Cuando son deportados, un porcentaje importante de migrantes mexicanos quedan separados de sus familiares cercanos -cónyuges e hijas/os- (véase la Gráfica 3), con los que eventualmente querrán reunirse en Estados Unidos. Al respecto, los hallazgos de la literatura son aparentemente contradictorios. Cardoso et al. (2016) analizan el caso de migrantes varones salvadoreños deportados, identificando a quienes fueron separados de esposas y/o hijos, y muestran que en- 
tre ellos hay una mayor propensión a tener planes de regreso a Estados Unidos respecto a los que no fueron separados de sus familias. Amuedo-Dorantes, Pozo y Puttitanun (2015), empleando datos de la Encuesta de Migración en la Frontera Sur (Emif Sur), encuentran que los centroamericanos deportados con hijos en Estados Unidos tienen una propensión mayor a mostrar intención de regresar a ese país en el corto y largo plazos. Sin embargo, Martínez, Slack y Martínez-Schuldt (2018) perciben que "dejar atrás" hijos en territorio estadounidense está asociado entre los migrantes mexicanos encuestados con una menor propensión a intentar reemigrar en la semana siguiente; consideran este fenómeno contraintuitivo, pero señalan que puede deberse a que estos padres y madres tratan de lograr una reunificación en Estados Unidos por vías legales, o que tenían la intención de traer a sus hijos a México (en contradicción con lo observado en los trabajos cualitativos antes mencionados).

Algunas de estas contradicciones no lo son tanto si se tiene en cuenta el hecho de que se trata de poblaciones y temporalidades distintas pues, como se ha podido observar con datos históricos de la Emif Norte y la Emif Sur, las intenciones de reemigrar a Estados Unidos varían de manera considerable entre las poblaciones mexicana y centroamericana, y a lo largo del tiempo conforme se producen cambios en las políticas migratorias estadounidenses.

De acuerdo con lo señalado anteriormente, enumeramos los siguientes resultados esperados: 1) Que el hecho de que permanezcan familiares en Estados Unidos con los que se tienen vínculos más estrechos (como hijas/os y cónyuges) esté relacionado con una mayor propensión a la intención de regresar a aquel país. Mientras que el que permanezcan familiares con vínculos menos estrechos (hermanas/os y otros parientes) no tendrá un efecto en uno u otro sentido sobre las intenciones de regresar. 2) Que el hecho de sufrir alguna de las consecuencias del sistema de deportación que criminaliza a los migrantes (quedar privado de la libertad de manera prolongada y recibir prohibición de reingreso) esté relacionado con una menor propensión a la intención de regresar a Estados Unidos, que entre quienes no las padecen. 


\section{Datos y metodología}

La metodología de la Encuesta sobre Migración en la Frontera Norte de México consiste en la observación continua, con base en un muestreo probabilístico, de diversos flujos en múltiples sitios. Los flujos se definen por su dirección y la condición del desplazamiento: 1) procedentes del sur; 2) procedentes del norte (de Estados Unidos o la frontera norte); y 3) devueltos por autoridades estadounidenses. Estos flujos se captan en localidades de la frontera norte. La zona fronteriza es un lugar idóneo para encuestar a los migrantes indocumentados, quienes durante muchos años han conformado gran parte de los flujos que entran en Estados Unidos. En este trabajo analizamos exclusivamente a los que son devueltos por autoridades estadounidenses, los cuales son entrevistados minutos después de ser recibidos en México.

La Emif Norte y sus módulos ha resultado un instrumento especialmente importante para estudiar lo que sucede con los migrantes mexicanos deportados de Estados Unidos, ya que permite conocer la evolución en la magnitud de deportados, realizar caracterizaciones sociodemográficas de esta población y valorar las implicaciones que esto tiene en términos de reinserción social y laboral (Calva y Coubès, 2017; Coubès, 2018; Velasco y Coubès, 2013). Asimismo, ha sido de especial utilidad para el análisis del fenómeno de la reemigración de quienes han sido previamente deportados por las autoridades (Bojórquez Chapela, González Fagoaga y Guillén López, 2014; Amuedo Dorantes y Pozo, 2014; Calva Sánchez y Alarcón Acosta, 2018).

El tamaño de la muestra de esta encuesta es considerablemente más grande que el de otros estudios sobre deportación en México, y es representativa de toda la población deportada a los puntos formales de repatriación. A partir de 2014 se diseñó un cuestionario con dos grandes secciones: una para los eventos relacionados con la población de expulsados residentes en México, y otra para los residentes en Estados Unidos. La agregación de los datos de 2017 y $2018^{8}$

${ }^{8}$ Para lograr una mayor robustez estadística se agregaron los datos recabados en 2017 y 2018, que son los dos únicos años para los que se dispone de la variable 
supone una muestra de 6825 casos, lo que permite analizar cada uno de estos grupos; para el segundo de éstos se tienen 1701 casos. $^{9}$

En lo que respecta a este trabajo, la amplitud muestral supone que la Emif Norte es la única encuesta existente que, hasta la fecha, permite analizar cabalmente cómo el sistema de deportación y el hecho de quedar separados de sus familiares están asociados con la intención de reemigrar de los varones ${ }^{10}$ mexicanos deportados por las autoridades estadounidenses y que residían en aquel país. Nuestro interés es la deportación de aquellos que, de facto, ya estaban residiendo en Estados Unidos, y cuyos planes migratorios van a estar configurados por el hecho de haberse establecido en aquel país; ello es una ventaja de este trabajo respecto a otros que analizan conjuntamente poblaciones de varones ya asentadas con otras poblaciones, cuyas experiencias migratorias pueden reducirse exclusivamente al intento de cruce y cuyos nexos con Estados Unidos son menores.

Otra de las aportaciones de este trabajo estriba en la necesidad de analizar qué sucede con la reemigración en un periodo (2017-2018) marcado por las políticas antiinmigrantes de Trump y que, como se ha señalado, muestra las expectativas de reingreso más bajas desde el año 2000 (Calva Sánchez y Alarcón Acosta, 2018); en contraste con el trabajo de Martínez, Slack y Martínez-Schuldt (2018), cuya base de datos se recabó mayormente en 2011, año en el cual la intención de reingreso era relativamente alta.

La Emif Norte contiene datos sobre la ubicación de las personas con las que el deportado tiene lazos fuertes (cónyuge, hijas/

prohibición del reingreso. Por tanto, los resultados dan cuenta de la situación de ambos años.

${ }^{9}$ Además, en cuestión de resultados las series históricas han mostrado una considerable consistencia interna y con respecto a escenarios que se pueden construir con otras fuentes, por ejemplo, el porcentaje de residentes en Estados Unidos entre los deportados, que tuvo un máximo en 2011, situación que se puede corroborar con otras fuentes, como se mostró anteriormente (véanse las Gráficas 1 y 2).

${ }^{10}$ Consideramos exclusivamente a los varones por tres razones: primero, suponen el grueso de las deportaciones de mexicanos desde Estados Unidos; segundo, las políticas migratorias estadounidenses afectan de manera diferenciada a hombres y mujeres; tercero, las estrategias migratorias de tránsito y cruce de fronteras difieren por sexo. 
hijos) y menos estrechos (otros familiares y amigos). En lo que respecta al sistema de deportación que criminaliza a los migrantes, la encuesta pregunta sobre el tiempo de detención del migrante por parte de las autoridades estadounidenses y sobre si el encuestado firmó su salida voluntaria -lo que supone salir del país de manera expedita-. Además, a partir de 2017 pregunta sobre el castigo que reciben los migrantes mexicanos, que limita la solicitud de ingreso documentado al territorio estadounidense.

Para el logro del objetivo propuesto en este trabajo, en primer lugar se realiza un análisis descriptivo de las intenciones de reingreso a Estados Unidos (ya sea en el corto plazo -menos de tres meses- o en algún momento de sus vidas) por parte de hombres residentes en aquel país y que fueron deportados por sus autoridades, en relación con si el encuestado cuenta con familiares en Estados Unidos y en función de variables referidas a la puesta en práctica del sistema de deportación que criminaliza a los migrantes. La intención de reingresar es un buen predictor de la realización de la acción de reingresar, pero, como es obvio, no todos los que declaran su intención finalmente lo hacen; y viceversa, los que no tienen intención de hacerlo, posteriormente pueden llegar a realizarlo (Amuedo-Dorantes, Pozo y Puttitanun, 2015; Cardoso et al., 2016).

En segundo lugar, se llevan a cabo dos modelos de regresión logística multivariados ${ }^{11}$ de la intención de los varones mexicanos deportados en 2017 y 2018, y residentes en Estados Unidos, de reingresar a aquel país en tres meses y algún día, ${ }^{12}$ respectivamente. Ambas variables dependientes son dicotómicas -sí o no- respecto de si

${ }^{11}$ Los modelos de regresión logística multivariados han sido repetidamente utilizados para analizar los factores asociados a la reemigración de migrantes deportados (Bojórquez Chapela, González Fagoaga y Guillén López, 2014; Cardoso et al., 2016; Martínez, Slack y Martínez-Schuldt, 2018).

${ }^{12}$ En la Emif Norte se pregunta sobre (1) la intención de retornar dentro de los próximos siete días; si el migrante responde de forma negativa, se pregunta sobre (2) la intención de retorno en los próximos tres meses; y, si nuevamente responde de forma negativa, se pregunta sobre (3) la intención de regresar en un periodo más largo de tiempo. La variable dependiente del primer modelo se compone de la agregación de las respuestas afirmativas a las dos primeras preguntas; y la del segundo modelo, de la suma de las respuestas afirmativas a las tres preguntas. 
el encuestado tiene entre sus planes a futuro la intención de reingresar a territorio estadounidense.

En estos dos modelos se prueban los efectos de variables relacionadas con la separación familiar: tener hija/s y/o hijo/s menores en Estados Unidos (HIEUA), tener esposa en Estados Unidos (ESEUA), tener esposa en México (ESMX), tener madre/padre en Estados Unidos (MPEUA), tener hermana/o (HEUA), y tener otro pariente en Estados Unidos (OEUA). Asimismo, se examinan los efectos de variables relativas al Consequence Delivery System: haber firmado una salida voluntaria (FIRMA), prohibición de reingreso al territorio estadounidense (PROHIB, recibió castigo o no) y tiempo de detención por parte de las autoridades migratorias estadounidenses (TD, si el encuestado pasó más de siete días detenido ${ }^{13}$ o no). Las variables de control utilizadas son la edad (EDAD, en años) y el dominio del idioma inglés (ING, habla inglés o no). Finalmente, se incluye una variable dicotómica para ver la diferencia entre ambos años (AÑO, si el encuestado fue devuelto en 2018).

Los modelos de regresión logística resultantes son:

Modelo 1: $\ln \frac{p_{\text {intención } 3 \text { meses }}(x)}{p_{\text {no intención 3 meses }}(x)}=\beta_{0}+\beta_{1} E D A D+\beta_{2} I N G+\beta_{3}$ FIRMA + $\beta_{4} P R O H I B+\beta_{5} T D+\beta_{6} H I E U A+\beta_{7} E S E U A+\beta_{8} E S M X+\beta_{9} M P E U A+$

$$
\beta_{10} H E U A+\beta_{11} O E U A+\beta_{12} A \tilde{N} O
$$

Modelo 2: $\ln \frac{p_{\text {intención algún dia }}(x)}{p_{\text {no intención }}(x)}=\beta_{0}+\beta_{1} E D A D+\beta_{2} I N G+\beta_{3}$ FIRMA +

$$
\begin{gathered}
\beta_{4} P R O H I B+\beta_{5} T D+\beta_{6} H I E U A+\beta_{7} E S E U A+\beta_{8} E S M X+\beta_{9} M P E U A+ \\
\beta_{10} H E U A+\beta_{11} O E U A+\beta_{12} A \tilde{N} O
\end{gathered}
$$

${ }^{13}$ Para la elección de este punto de corte de siete días seguimos lo señalado por Martínez, Slack y Martínez-Schuldt (2018) para diferenciar en cuanto a los migrantes bajo detención por la patrulla fronteriza, que no suele superar la semana, y aquellos que pasan tiempos de encarcelamiento más largos. 


\section{Resultados y análisis}

En el Cuadro 1 se presentan las características que se consideraron para este análisis, las cuales se resumieron en variables dicotómicas (presencia y ausencia de la característica). El grupo de migrantes encuestados en la Emif Norte se dividió a partir de cada una de estas variables y se calculó la distribución porcentual según su intención de regresar a Estados Unidos. Los resultados revelan que 28.2\% de los encuestados en el flujo de deportados intentarán regresar en tres meses o menos tiempo, y que cerca de la mitad reportan que lo procurarán en ese periodo o lo harán algún día ${ }^{14}(47.6 \%)$. En el primer caso (hasta en tres meses), presumiblemente la inmensa mayoría de las personas realizarán un cruce indocumentado (lo que implica asumir riesgos de diverso tipo: económicos, legales, a la integridad física, entre otros) porque más de una quinta parte de ellos tienen planes de hacerlo en siete días o menos $(21.2 \%)^{15}$-tiempo en el cual no hay forma de lograr una visa- y cerca del $77.1 \%$ recibieron una prohibición de reingreso -lo que suele implicar una espera de años de zozobra y trámites para, llegado el caso, lograr reingresar legalmente-. Aunque posiblemente el cruce indocumentado siga siendo el escogido mayoritariamente entre los que tienen planes de regresar algún día, en este caso sí caben las diferentes opciones legales, aunque en algunas ocasiones las esperas sean de incluso décadas.

En el Cuadro 1 se abordan cuatro ejes temáticos: características del migrante (asociadas a su posible integración social en dicho país), variables relativas al sistema de deportación que criminaliza a los migrantes indocumentados, lazos familiares y año en cuestión. Para analizar la posible relación de estas variables con el propósito de retorno, se comparan las respuestas de la población que presenta estas características respecto a la que no las presenta y en relación al total de la población. En el primer eje, que incluye la variable hablar inglés, se identifica una diferencia respecto a la intención de regresar en tres meses a ese país (25.9\%), frente a quienes no presentan ese propósito (31.4\%).

${ }^{14}$ Se hace notar que "algún día" incluye a los que intentarán regresar antes de tres meses.

${ }^{15}$ Este dato no se recoge en el cuadro.

Estudios Demográficos y Urbanos, vol. 36, núm. 2 (107), mayo-agosto, 2021, pp. 637-672 http://dx.doi.org/10.24201/edu.v36i2.1971 


\section{Cuadro 1}

Intención de reingreso a Estados Unidos de hombres mexicanos deportados, según características seleccionadas y temporalidad de los planes de regreso; 2017 y 2018

\begin{tabular}{|c|c|c|c|c|}
\hline \multirow[b]{2}{*}{ Variables } & \multirow[b]{2}{*}{ Respuesta } & \multirow[b]{2}{*}{ Casos } & \multicolumn{2}{|c|}{ Intentará regresar } \\
\hline & & & en 3 meses & algún día \\
\hline \multirow[t]{2}{*}{ Habla inglés } & No & 710 & 31.4 & 46.6 \\
\hline & Sí & 991 & 25.9 & 48.2 \\
\hline \multirow[t]{2}{*}{ Prohibición reingreso a EU } & No & 391 & 36.6 & 56.3 \\
\hline & Sí & 1297 & 25.7 & 44.7 \\
\hline \multirow[t]{2}{*}{ Firmó salida voluntaria } & No & 913 & 17.4 & 38.2 \\
\hline & Sí & 783 & 40.9 & 58.5 \\
\hline \multirow[t]{2}{*}{ Detención más de 7 días en EU } & No & 390 & 59.7 & 77.9 \\
\hline & Sí & 1300 & 18.7 & 38.5 \\
\hline \multirow{2}{*}{ Tiene cónyuge en EU } & No & 1317 & 26.0 & 42.4 \\
\hline & Sí & 384 & 35.9 & 65.4 \\
\hline \multirow{2}{*}{ Tiene cónyuge en México } & No & 1273 & 27.3 & 49.3 \\
\hline & Sí & 428 & 31.1 & 42.5 \\
\hline \multirow{2}{*}{ Tiene hijos menores en EU } & No & 1172 & 25.8 & 42.8 \\
\hline & Sí & 528 & 33.5 & 58.0 \\
\hline \multirow{2}{*}{ Tiene padre / madre en EU } & No & 1347 & 29.5 & 46.8 \\
\hline & Sí & 354 & 23.2 & 50.3 \\
\hline \multirow[t]{2}{*}{ Tiene hermanas/os en EU } & No & 734 & 24.1 & 43.2 \\
\hline & Sí & 967 & 31.3 & 50.9 \\
\hline \multirow[t]{2}{*}{ Tiene otros parientes en EU } & No & 1448 & 29.6 & 47.0 \\
\hline & Sí & 253 & 20.6 & 50.6 \\
\hline \multirow[t]{2}{*}{ Fue devuelto en 2018} & No (2017) & 1097 & 26.8 & 45.2 \\
\hline & Sí (2018) & 604 & 30.8 & 51.8 \\
\hline Total & & 1701 & 28.2 & 47.6 \\
\hline
\end{tabular}

Fuente: Elaboración propia con base en la Emif Norte, 2017 y 2018.

Respecto al sistema de deportación, las variables incluidas en el análisis producen diferencias relevantes en la intención de retorno para las dos temporalidades consideradas. Entre los hombres deportados que no recibieron una prohibición de reingreso a Estados Unidos se identifica que $36.6 \%$ intentarían regresar a ese país en tres 
meses o menos, y 56.3\% señalan que regresarán algún día; en ambos casos los porcentajes son superiores a los de la población en general y más aún respecto de aquellos que tienen que enfrentar la prohibición de reingreso (con 25.7 y $44.7 \%$, respectivamente). Por su parte, haber firmado la salida voluntaria implica diferencias todavía mayores, ya que $40.9 \%$ de los que lo hicieron indican que volverán a intentar cruzar en el corto plazo, y en el caso de algún día, el porcentaje es 58.5; este resultado es consistente con la hipótesis de que quienes firman la salida voluntaria lo hacen para regresar lo más pronto posible. Finalmente, en lo que respecta al tiempo de detención, también se muestra una relación con la intención de retorno, ya que sólo $18.7 \%$ de quienes pasaron más tiempo detenidos indican que intentarán cruzar en el corto plazo, y entre quienes pasaron menos tiempo detenidos el porcentaje se triplica (59.7\%).

En lo que concierne a los lazos familiares, tener parientes cercanos en Estados Unidos resulta un claro aliciente para que los hombres deportados quieran regresar a ese país. Tener hijas/hijos menores de edad y tener cónyuge en aquel país está relacionado con porcentajes más altos en la intención de retorno tanto en el "corto plazo" (35.9 y $33.5 \%$, respectivamente) como en el "corto o largo plazo" (65.4 y $58.0 \%$, respectivamente) que entre quienes no los tienen.

Aunque en menor medida, tener hermanas/os en el territorio estadounidense supone un mayor aliciente para intentar reingresar. En contraste, tener padre/madre y otros parientes no muestra diferencias destacables. En el análisis de los lazos familiares se consideró además la presencia del cónyuge en México, pues una deportación también podría implicar una reunificación familiar, aunque resulta que los varones con cónyuge en México no muestran grandes diferencias con respecto a quienes no tienen.

En los que respecta al año de devolución, se puede observar que en 2018 se produjo un auge no muy destacado en cuanto a la intención de regresar, pues pasó del 26.8 al $30.8 \%$ en lo que respecta a los próximos tres meses y algún día (de 45.2 a 51.8\%).

En el Cuadro 2 se muestran los resultados de los modelos de regresión logística respecto a la intención de regresar en los próximos tres meses y algún día, presentados en términos de momios (es decir, los exponenciales de los coeficientes). Las variables independientes 
de interés se agrupan bajo dos ejes: el sistema de deportación que criminaliza a los inmigrantes indocumentados y las referidas a los lazos familiares.

\section{Cuadro 2}

Razones de momios estimadas de las características seleccionadas que, en los hombres mexicanos deportados, predicen la intención de regresar a EU en tres meses y en algún día

\begin{tabular}{|c|c|c|}
\hline \multirow[b]{2}{*}{ Variables } & \multicolumn{2}{|c|}{ Intentará regresar en } \\
\hline & tres meses & algún día \\
\hline \multicolumn{3}{|l|}{ Sociodemográficas } \\
\hline Edad & $0.99 \mathrm{~ns}$ & $0.98 * * *$ \\
\hline Habla inglés & $0.79 *$ & $0.94 \mathrm{~ns}$ \\
\hline \multicolumn{3}{|l|}{ Sistema de deportación que criminaliza } \\
\hline Prohibición de reingreso a EU & $0.88 \mathrm{~ns}$ & $0.80^{*}$ \\
\hline Firmó salida voluntaria & $2.18 * * *$ & $1.81 * * *$ \\
\hline Detención de más de 7 días en EU & $0.20 * * *$ & $0.21 * * *$ \\
\hline \multicolumn{3}{|l|}{ Lazos familiares } \\
\hline Hijos menores en EU & $1.51 * * *$ & $1.57 * * *$ \\
\hline Tiene cónyuge en EU & $1.37 *$ & $2.23 * * *$ \\
\hline Tiene cónyuge en México & $0.85 \mathrm{~ns}$ & $0.63 * * *$ \\
\hline Tiene padre / madre en EU & $0.73 *$ & $0.97 \mathrm{~ns}$ \\
\hline Tiene hermanas/os en EU & $1.54 * * *$ & $1.57 * * *$ \\
\hline Tiene otros parientes en EU & $0.78 \mathrm{~ns}$ & $1.70 * * *$ \\
\hline \multicolumn{3}{|l|}{ Año } \\
\hline Fue devuelto en 2018 & $1.34 * *$ & $1.53 * * *$ \\
\hline Constante & $0.95 \mathrm{~ns}$ & $2.65 * * *$ \\
\hline McFadden's pseudo R2 & 0.16 & 0.14 \\
\hline $\mathrm{N}$ & 1673 & 1673 \\
\hline
\end{tabular}

$* \mathrm{p}<0.10 ; * * \mathrm{p}<0.05 ; * * * \mathrm{p}<0.01$

ns: no significativo.

Fuente: Elaboración propia con base en la Emif Norte, 2017 y 2018.

En lo referente a las variables del perfil del individuo, resulta hasta cierto punto inesperado que quienes hablan inglés sean menos propensos a tener la expectativa de cruzar la frontera en tres meses o 
menos tiempo ( $21 \%$ menos); esto se observa sólo para ese modelo, en el otro la variable no resultó significativa. Debido a este resultado, se puso especial énfasis en identificar posibles explicaciones de este resultado. Se analizaron las variables sobre intención de retorno para los dos años por separado, y se identificó que en particular en 2017 hubo una mayor intención de retorno entre quienes no sabían inglés: $19.7 \%$ indica que intentará cruzar en siete días o menos, respecto a $14.0 \%$ de quienes no saben inglés. Tal resultado está asociado con el tiempo de la última estancia, ya que quienes no hablan inglés y pretenden regresar pasaron menos tiempo en Estados Unidos respecto a quienes pretenden hacerlo (las medianas en años son 5 y 12 años, respectivamente), por lo que estos últimos posiblemente desconozcan la situación actual de la frontera norte de México y las posibilidades del cruce indocumentado. Sin embargo, es un tema que hay que seguir analizando y contemplar los resultados de la encuesta para 2019.

Respecto al resto de las variables consideradas en el modelo, según los resultados el sistema de deportación afecta los planes de los migrantes indocumentados, tanto en el modelo para la intención de retorno en los tres próximos meses, como en el que identifica la intención de retorno sin determinar un periodo de tiempo (algún día). Entre las variables asociadas al sistema de deportación, el tiempo de detención resultó tener el mayor efecto negativo: la intención de reingreso en los próximos tres meses es $80 \%$ menor para los que son detenidos por más de siete días respecto de los detenidos por un tiempo menor. ${ }^{16}$ La diferencia es similar cuando se trata de planes de regresar algún día (79\% menor). El poder disuasorio que encontramos produce este trato a los migrantes (como delincuentes a los que se mantiene privados de su libertad) es consistente con lo señalado por Martínez, Slack y Martínez-Schuldt (2018) para la población mexicana en general. Asimismo, se observa que, entre quienes reciben la prohibición de reingreso a Estados Unidos, la propensión a mostrar intención de regreso sería $20 \%$ menor frente a los que no la reciben, pero el modelo de tres meses no arroja evidencia estadísticamente significativa para sostener que esto mismo suceda en

16 Todas las interpretaciones se realizan bajo a la asunción de que se mantienen constantes las restantes variables explicativas. 
esa periodicidad. En cualquier caso, la mayor parte de los resultados apuntan a que las consecuencias del sistema de deportación hacen mella en la voluntad de los migrantes para reingresar a Estados Unidos, en consonancia con lo observado en el análisis descriptivo.

En contraste con los castigos del sistema de deportación, el firmar su salida voluntaria revela la propensión a reingresar a Estados Unidos de más del doble (2.18 veces mayor) en el caso de tres meses, y de 1.81 veces mayor en el caso de algún día. Esta evidencia sugiere que muchos de los que firman su salida voluntaria, además de no sufrir algunos de los perjuicios del sistema de deportación antes mencionados, cuentan con algún plan para lograr un reingreso exitoso en el corto plazo (por ejemplo, un "coyote" de confianza), lo que les hace tratar de salir del proceso de deportación lo antes posible y con las menores repercusiones en caso de una nueva deportación. Asimismo, tendrán menos dificultades para optar por una vía legal de cruce en cualquier momento del futuro.

Respecto a las variables familiares, la presencia de hijos menores en ese país es significativa en la intención de retornar a Estados Unidos, tanto en el modelo de retorno en tres meses como en el de algún día, ya que supone una propensión a intentar regresar $1.51 \mathrm{y}$ 1.57 veces mayor, respectivamente, en comparación con quienes no tienen hijos menores en aquel país. Por su parte, tener cónyuge en Estados Unidos implica una propensión a considerar el regreso en el corto o largo plazo, pues es 2.23 veces mayor en el modelo de algún día. Por el contrario, tener cónyuge en México muestra que la propensión de la intención de retorno a Estados Unidos es 37\% menor (al 10\% de significancia estadística). Estos resultados respecto a los familiares con los que se establecen lazos fuertes corroboran las evidencias del análisis descriptivo en cuanto a la importancia de esta clase de vínculos para entender las intenciones de reingreso a Estados Unidos. Como era esperado, tener familiares cercanos que se quedan en dicho país supone que los migrantes muestren una mayor propensión para retornar a aquél. Y bajo la misma lógica, tienden a permanecer en México si cuentan con familiares cercanos en este país tras la deportación. Además, estos resultados son consistentes tanto con las evidencias de numerosas investigaciones de corte cualitativo, como con los resultados de los trabajos cuantitativos con 
migrantes centroamericanos (Amuedo-Dorantes, Pozo y Puttitanun, 2015; Cardoso et al., 2016), y hacen, si cabe, más contrastantes los resultados obtenidos por Martínez, Slack y Martínez-Schuldt (2018) en cuanto a que tener hijos en Estados Unidos implica una menor propensión a querer regresar a aquel país.

En lo referente a familiares menos cercanos, destaca el hecho de que tener hermanas/os en Estados Unidos implique propensiones de 1.54 veces mayor a regresar en tres meses y 1.57 veces mayor a regresar algún día, que quienes no los tienen. Más llamativa es la evidencia de que tener padre o madre en Estados Unidos afecte de manera negativa (al 10\%) a la intención de regreso antes de tres meses. Todos estos resultados contrastan con nuestra expectativa de que no afectaran los planes de retorno al territorio estadounidense.

Un último aspecto a resaltar es que la propensión al retorno en 2018 es considerablemente mayor a la de 2017 , con independencia de si la intención de reingreso es en tres meses o algún día, en el mismo sentido que lo observado en el Cuadro 1.

\section{Comentarios finales}

En los años posteriores al inicio de la crisis económica de 2008, se observó un incremento en el número de deportaciones de mexicanos desde Estados Unidos, específicamente de aquellos que tenían más tiempo residiendo en aquel país. En 2011 se registró el mayor número de eventos de este tipo (176 mil según datos de la Emif Norte); posteriormente, en 2016, el fenómeno descendió a menos de 49 mil; pero con la llegada de Trump a la presidencia de Estados Unidos, el monto aumentó a 60 mil en 2017 y se mantuvo en una cifra similar para 2018 (58 mil). En el proceso de deportación muchos hombres afrontan privaciones de su libertad y reciben sanciones que les prohíben el reingreso a Estados Unidos por cierto tiempo o de por vida. Durante el tiempo que dura el castigo no sólo es imposible obtener una visa para reingresar al territorio estadounidense, sino que en caso de cruzar de manera irregular y ser detenido, se pueden enfrentar cargos criminales y penas de prisión. Además, un alto porcentaje de las expulsiones conllevan la separación familiar y esto ocurre con más 
frecuencia entre los hombres; como consecuencia, miles de padres mexicanos quedan separados de sus hijos (cerca del $30 \%$ si se considera a los padres expulsados en 2018 que son separados de sus hijos menores de edad).

Este trabajo arroja evidencia robusta en favor de considerar que la política migratoria estadounidense mediante un sistema de deportación que criminaliza a los migrantes indocumentados tiene cierto grado de eficacia. Entre los factores que afectan de forma negativa al reingreso destaca haber sido detenido más de siete días respecto a quienes permanecen menos tiempo. Hay que seguir indagando sobre las causas y condiciones en que suceden las estancias más prolongadas y verificar si esto no es parte de una práctica de hostigamiento de las autoridades estadounidenses hacia los migrantes para desincentivar futuros cruces. Destaca que la prohibición del reingreso tiene un peso menor en explicar la intención de retorno e incluso no significativa en el corto plazo. Esto es indicativo de que quienes regresan con mayor prontitud, y presumiblemente sin documentos, son personas que por unas razones u otras están más dispuestas a asumir los riesgos que ello implica.

Sin embargo, en ningún caso la efectividad de cierta política pública debe ser el único criterio para su valoración. En este sentido, los programas y medidas que criminalizan a los migrantes son injustos, e inclusive se puede considerar que constituyen una forma de violencia estructural en su contra.

En contraposición al sistema de migración punitivo, las relaciones familiares son factores que alientan el reingreso a Estados Unidos, y los resultados son los esperados, es decir, positivos: la presencia de hijos o cónyuge en ese país supone una mayor propensión a que el migrante tenga la intención de reingresar en ambos modelos (tres meses y algún día). Aunque los padres no experimentan la misma presión social que las madres para que estén siempre y en todo lugar con sus hijas/os, encontramos que también hacen grandes sacrificios por tener una paternidad cercana a ellas/os. Como prueba de esto, observamos que los padres mexicanos que tienen hijas/os menores de edad en territorio estadounidense respecto a quienes no los tienen en aquel territorio (o no son padres), son considerablemente más propensos a intentar el cruce en los próximos tres meses, lo que 
supone que están en mayor medida dispuestos a afrontar los riesgos que implica el cruce indocumentado con tal de estar junto a sus hijos.

Una de las limitantes de la Emif Norte es que no tiene información sobre la edad de los hijos y sobre el estatus migratorio de los integrantes que quedan en territorio estadounidense, ambos considerados factores relevantes para entender las movilidades migratorias tras la deportación. Por ejemplo, un hombre deportado que quedó separado de un/a recién nacido/a en Estados Unidos posiblemente tenga mayor deseo de reingresar en el menor tiempo posible -por más que se le haya prohibido el reingreso- respecto a quien tiene un/a hijo/a adolescente, menos dependiente del padre. Además, si el/ la hijo/a es ciudadano estadounidense y está próximo a ser mayor de edad, podría solicitar una visa de residente para su padre en cuanto cumpla 21 años, lo que puede llevar al deportado a decidir permanecer en México y esperar esa oportunidad. Por la misma razón, sería interesante indagar según el estatus legal de la madre.

Uno de los posibles efectos de la deportación que no se menciona con tanta frecuencia es la reunificación familiar en México, ya que, paradójicamente, las expulsiones de varones desde Estados Unidos también pueden conducir a una reunificación, lo que, de acuerdo con nuestro modelo, disminuye la propensión a querer salir de México (al menos algún día) con destino al territorio estadounidense. Estas reunificaciones provocadas por la deportación deberán ser abordadas en mayor detalle por futuras investigaciones, pues la manera en que se producen también puede generar conflictos, ya que el retorno del varón sin haber logrado los objetivos migratorios puede "arruinar" ciertos proyectos familiares.

\section{Bibliografía}

Abrego, L., Coleman, M., Martínez, D., Menjívar, C. y Slack, J. (2017). Making immigrants into criminals: Legal processes of criminalization in the post-IIRIRA era. Journal on Migration and Human Security, 5(3), 694-715. https://journals.sagepub. com/doi/pdf/10.1177/233150241700500308 
Albicker, S. y Velasco, L. (2016). Deportación y estigma en la frontera México-Estados Unidos: atrapados en Tijuana. Norteamérica, 11(1), 99-129. http:/www.scielo.org.mx/scielo.php?script=sci arttext\&pid=S1870-35502016000100099

American Immigration Council. (2012). Falling through the cracks. Immigration Policy Center. https://www.americanimmigration council.org/research/falling-through-cracks

Amuedo-Dorantes, C. y Pozo, S. (2014). On the intended and unintended consequences of enhanced U.S. border and interior immigration enforcement: Evidence from Mexican deportees. Demography, 51(6), 2255-2279. https:/www.ncbi.nlm.nih.gov/ pubmed/25361892

Amuedo-Dorantes, C., Pozo, S. y Puttitanun, T. (2015). Immigration enforcement, parent-child separations, and intent to remigrate by Central American deportees. Demography, 52(6), 1825-1851. https:/www.ncbi.nlm.nih.gov/pubmed/26471281

Argueta, C. (2016). Border security: Immigration enforcement between ports of entry, Congressional Research Service. https:// fas.org/sgp/crs/homesec/R42138.pdf

Bojórquez Chapela, I., González Fagoaga, E. y Guillén López, T. (2014). Estado de salud e intención de volver a Estados Unidos en migrantes mexicanos: ¿evidencia de un sesgo de retorno selectivo? Estudios Demográficos y Urbanos, 29(1), 165-182. https: //estudiosdemograficosyurbanos.colmex.mx/index.php/edu/article/view/1458/1451

Calva, L. y Coubès, M. (2017). Desaceleración de la dinámica migratoria: descenso generalizado de los flujos de salida y de retorno de migrantes mexicanos. En La situación demográfica de México (pp. 209-220). Ciudad de México: Consejo Nacional de Población. https:/www.gob.mx/cms/uploads/attachment/ file/232083/09_Calva_Coubes.pdf

Calva Sánchez, L. y Alarcón Acosta, R. (2018). Migrantes mexicanos deportados y sus planes para reingresar a Estados Unidos al inicio del gobierno de Donald Trump. Revista Mexicana de Ciencias Políticas y Sociales, 63(233), 43-68. http://www.scielo. org.mx/pdf/rmcps/v63n233/0185-1918-rmcps-63-233-43.pdf 
Capps, R., Koball, H., Campatella, A., Perreira, K., Hooker, S. y Pedroza, J. M. (2015). Implications of immigration enforcement activities for the well-being of children in immigrant families. A review of the literature. Reporte de investigación. Urban Institute / Migration Policy Institute. https://www.urban.org/sites/ default/files/alfresco/publication-exhibits/2000405/2000405Implications-of-Immigration-Enforcement-Activities-for-theWell-Being-of-Children-in-Immigrant-Families.pdf

Cardoso, J., Randle, E., Rodriguez, N., Eschbach, K. y Hagan, J. (2016). Deporting fathers: Involuntary transnational families and intent to remigrate among Salvadoran deportees. The International Migration Review, 15(1), 197-230. https://online library.wiley.com/doi/full/10.1111/imre.12106

Cornelius, W. A. (2007). Una década experimentando con una política. Control de la inmigración no deseada. En E. Cabrera (ed.), Desafios de la migración. Saldos de la relación México-Estados Unidos (pp. 251-282). Ciudad de México: Planeta.

Coubès, M. (2018). Deportaciones de mexicanos desde Estados Unidos: ¿qué está cambiando con el nuevo gobierno de Estados Unidos? Coyuntura Demográfica, 13, 87-95. http://coyuntura demografica.somede.org/wp-content/plugins/coyuntura_demo grafica/COMPLETAS/13.pdf

Department of Homeland Security, Office of Immigration Statistics (2017). Yearbook of immigration statistics: 2016. Washington, D.C. https://www.dhs.gov/immigration-statistics/yearbook/2017 Dreby, J. (2012). The burden of deportation on children in Mexican immigrant families. Journal of Marriage and Family, 74(4), 829-845. https://onlinelibrary.wiley.com/doi/full/10.1111/ j.1741-3737.2012.00989.x

Emif Norte. (2000-2018). Bases de datos. Encuestas sobre migración en las fronteras norte y sur de México [en línea]. México: El Colegio de la Frontera Norte / Secretaría del Trabajo y Previsión Social / Consejo Nacional de Población / Instituto Nacional de Migración / Secretaría de Relaciones Exteriores. https://www. colef.mx/emif/

Ewing, W., Martínez, D. y Rumbaut, G. (2015). The criminalization of immigration in the United States. American Immigration 
Council. https://www.americanimmigrationcouncil.org/research /criminalization-immigration-united-states

Giddens, A. (2000). Sociología. España: Alianza.

Golash-Boza, T. y Hondagneu-Sotelo, P. (2013). Latino immigrant men and the deportation crisis: A gendered racial removal program. Latino Studies, 11(3), 271-292. https://link.springer.com/ article/10.1057/1st.2013.14

Hagan, J., Eschbach, K. y Rodriguez, N. (2008). U.S. deportation policy, family separation, and circular migration. The International Migration Review, 42(1), 64-88. https://www.jstor.org/stable /27645716?seq=1\#metadata_info_tab_contents

Hagan, J., Rodriguez, N. y Castro, B. (2011). Social effects of mass deportations by the United States government, 2000-2010. Ethnic and Racial Studies, 34(8), 1374-1391. https://www.tandfon line.com/doi/full/10.1080/01419870.2011.575233

IIRIRA (1996) Illegal Immigration Reform and Immigrant Responsibility Act of 1996. https:/www.congress.gov/104/crpt/hrpt828/ CRPT-104hrpt828.pdf

Mariscal Nava, D. M. y Torre Cantalapiedra, E. (2018). Cinco elementos clave para entender la (re)inserción laboral de los migrantes retornados en México en el último decenio. Ser Migrantes OIM, 5, 24-37. https:/www.academia.edu/36871431/Cinco_ele mentos_clave_para_entender_la_re_inserci\%C3\%B3n_laboral de_los_migrantes_retornados_en_M\%C3\%A9xico_en_el_\% C3\%BAltimo_decenio

Márquez Covarrubias, H. (2013). El redoble de la migración forzada: inseguridad, criminalización y destierro. Migración y Desarrollo, 11(21), 159-175. https://www.redalyc.org/pdf/660/660 29968007.pdf

Martínez Ahrens, J. (2017). Trump abre la puerta a las deportaciones masivas de indocumentados. El País. España. https://elpais.com/ internacional/2017/02/21/estados_unidos/1487691683_765713. html

Martínez, D., Slack, J. y Martínez-Schuldt, R. (2018). Repeat migration in the age of the "unauthorized permanent resident": A quantitative assessment of migration intentions posdeporta- 
tion. International Migration Review, 52(4), 1186-1217. https:// journals.sagepub.com/doi/pdf/10.1177/0197918318767921

Massey, D., Durand, J. y Riosmena, F. (2006). Capital social, política social y migración desde comunidades tradicionales y nuevas comunidades de origen en México. Revista Española de Investigaciones Sociológicas, Reis, 116, 97-121. https://www.redalyc. org/pdf/997/99715259003.pdf

Massey, D. y Espinosa, K. (1997). What's driving Mexico-U.S. migration? A theoretical, empirical, and policy analysis. American Journal of Sociology, 102(4), 939-999. https://www.jstor.org/ stable/2782024?seq=1\#metadata_info_tab_contents

Massey, D. y Riosmena, F. (2010). Undocumented migration from Latin America in an era of rising U.S. enforcement. The Annals of the American Academy of Political and Social Science, 630(1), 294-321. https://journals.sagepub.com/doi/pdf/10.1177 /0002716210368114

Meissner, D., Kerwin, D., Chishti, M. y Bergeron, C. (2013). Immigration enforcement in the United States: The rise of a formidable machinery. Reporte de investigación. Washington, D.C: Migration Policy Institute. http://www.migrationpolicy.org/research/immigra tion-enforcement-united-states-rise-formidable-machinery

Morales Guzmán, E. (2010). Imprisonment, deportation, and family separation: My American nightmare. Social Justice, 36(2), 106-109. https://www.jstor.org/stable/29768541?seq=1\#metadata_info tab_contents

Peláez Rodríguez, D. C. y París Pombo, M. D. (2016). Deportación femenina y separación familiar: experiencias de mexicanas deportadas a Tijuana. En E. Levine, S. Nuñez y M. Verea (coords.), Nuevas experiencias de la migración de retorno (pp. 59-80). Ciudad de México: UNAM, CISAN / Instituto Matías Romero, SRE.

Rosenblum, M., Meissner, D., Bergeron, C. y Hipsman, F. (2014). The deportation dilemma: Reconciling tough and humane enforcement. Reporte de investigación. Washington D.C.: Migration Policy Institute. http://www.migrationpolicy.org/research/deporta tion-dilemma-reconciling-tough-humane-enforcement 
Ruiz Marrujo, O. (2014). Undocumented families in times of deportation at the San Diego-Tijuana border. Journal of Borderlands Studies, 29(4), 391-403. https://www.tandfonline.com/doi/full/1 0.1080/08865655.2014.982469

Shear, M., Goodnough, A. y Haberman, M. (2018). Trump retreats on separating families, but thousands may remain apart. The New York Times. https://www.nytimes.com/2018/06/20/us/politics/trumpimmigration-children-executive-order.html?ref=nyt-es

Slack, J., Martínez, D., Whiteford, S. y Peiffer, E. (2015). In harm's way: Family separation, immigration enforcement programs, and security on the US-Mexico border. Journal on Migration and Human Security, 3(2), 109-128. https://journals.sagepub. com/doi/10.1177/233150241500300201

Stumpf, J. (2006). The crimmigration crisis: Immigrants, crime, and sovereign power. American University Law Review, 56(2), 367419. https://digitalcommons.wcl.american.edu/cgi/viewcontent. cgi?article $=1274 \&$ context $=$ aulr

Torre Cantalapiedra, E. y Rodríguez Gutiérrez, M. (2019). Paternidades a distancia: malestares de padres separados de sus hijas e hijos tras la deportación. Estudios Fronterizos, 20, 1-22. https:// doi.org/10.21670/ref.1902023

Velasco, L. y Coubès, M. (2013). Reporte sobre dimensión, caracterización y áreas de atención a mexicanos deportados desde Estados Unidos. México: El Colegio de la Frontera Norte. https:// www.colef.mx/estudiosdeelcolef/reporte-sobre-dimensioncaracterizacion-y-areas-de-atencion-mexicanos-deportadosdesde-estados-unidos

Wessler, S. (2011). Familias destrozadas. La intersección peligrosa de la aplicación de las leyes de inmigración y el sistema de cuidado infantil. Resumen Ejecutivo. Applied Research Center. http://www.ncdsv.org/images/ARC_ShatteredFamiliesPerilous IntersectionImmigEnforceChildWelfareSystem_ExSum_Span ish_11-11.pdf 


\section{Acerca de los autores}

Eduardo Torre Cantalapiedra es doctor en Estudios de Población por El Colegio de México, A.C. Es investigador Cátedras Conacyt adscrito a El Colegio de la Frontera Norte, sede Tijuana. Pertenece al Sistema Nacional de Investigadores, nivel I. Su investigación versa sobre migración internacional, políticas públicas y patrones migratorios. ORCID: https://orcid.org/0000-0002-4074-3752

Entre sus publicaciones recientes se encuentran:

Torre Cantalapiedra, E. (2020). Destino y asentamiento en México de los migrantes y refugiados centroamericanos. Trace, 77. 122145. http://trace.org.mx/index.php/trace/article/view/726

Torre Cantalapiedra, E. (2020) ¿Coyotes o defensores de migrantes? Criminalización del activismo promigrante en tiempos de caravanas. Revista da Mobilidade Humana, 28(58), pp. 51-67. https: //doi.org/10.1590/1980-85852503880005804

Méroné, S. C. y Torre Cantalapiedra, E. (2020). Estrategias de familias migrantes haitianas para sus hijos ante las políticas anti-inmigrantes de República Dominicana. Migraciones Internacionales, 11, 1-23. http://dx.doi.org/10.33679/rmi.v1i1.1742

Luis Enrique Calva Sánchez es actuario por la Universidad Nacional Autónoma de México (UNAM), maestro en Demografía por El Colegio de la Frontera Norte (Colef), y doctor en Ciencias Sociales por la misma institución. Ha sido profesor en la UNAM, en la Universidad de las Américas (Ecuador) y en el Colef. Desde 2014 participa en el proyecto del Observatorio Estadístico de la Migración entre Centroamérica, México y Estados Unidos. Actualmente está adscrito al Departamento de Estudios de Población del Colef, sede Monterrey. Forma parte del Sistema Nacional de Investigadores, nivel I. Las investigaciones que ha realizado se enfocan en el estudio de la migración de mexicanos a Estados Unidos y la migración en tránsito por México. ORCID: https://orcid.org/0000-0002-70375874

Entre sus publicaciones destacan:

Calva Sánchez, L. E. y Alarcón Acosta, R. (2018). Migrantes mexicanos deportados y sus planes para reingresar a Estados Uni- 
dos al inicio del gobierno de Donald Trump. Revista Mexicana de Ciencias Politicas y Sociales, 63(233), 43-68. https://doi. org/10.22201/fcpys.2448492xe.2018.233.62603

Calva Sánchez, L. E. y Torre Cantalapiedra, E. (2020). Cambios y continuidades en la política migratoria durante el primer año del gobierno de López Obrador. Norteamérica, Revista Académica del CISAN-UNAM, 15(2). https://doi.org/10.22201/cisan. 24487228e.2020.2.415

Recepción: 12 de junio de 2019. Aceptación: 21 de noviembre de 2019. 